\title{
Synthesis and Degradation of Hyaluronic Acid in the Cultured Fibroblasts of Marfan's Disease
}

\author{
Stanford I. Lamberg and Albert Dorfman \\ From the Departments of Medicine, Pediatrics, and Biochemistry, The Joseph \\ P. Kennedy Jr. Mental Retardation Center and the LaRabida-University of \\ Chicago Institute, The Pritzker School of Medicine, University of Chicago, \\ Chicago, Illinois 60637
}

A B S TRACT Increased amounts of hyaluronic acid accumulate in fibroblasts cultured from patients with Marfan's disease, an autosomal dominant disorder. In the recessive Hurler's disease, the storage of glycosaminoglycan (GAG) is due to impaired degradation. This study examines the kinetics of GAG accumulation in Marfan's disease in order to determine whether the mechanism of accumulation differs from that in Hurler's disease.

Marfan-derived fibroblasts incorporated $\left[{ }^{14} \mathrm{C}\right]$ acetate or $\left[{ }^{14} \mathrm{C}\right]$ glucosamine into $\mathrm{GAG}$ to a level 4-6 times greater than control fibroblasts. Sugar analyses, electrophoretic mobility, and enzyme susceptibility studies showed that the isolated material was hyaluronic acid. There were no differences in activity of a variety of glycosidases between Marfan and control fibroblasts, nor were there differences in the ability to degrade prelabeled hyaluronate by cell-free extracts. Finally, chase experiments showed parallel rates of loss of labeled GAG from control fibroblasts and fibroblasts from Marfan patients.

It appears that hyaluronic acid was accumulating in greater amounts in the fibroblasts from patients with Marfan's disease because of a greater rate of synthesis as opposed to a decreased rate of breakdown.

\section{INTRODUCTION}

Marfan's syndrome, an autosomal dominant disease, is characterized by defects in connective tissue including dislocated lenses, long extremities, loose-jointedness, aortic aneurysm, and mitral regurgitation (1). The molecular defect responsible for the pathology has not yet been established. Macek, Hurych, Chvapil, and Kad-

Received for publication 29 March 1973 and in revised form 4 June 1973. lecová found an increased ratio of $0.14 \mathrm{M} \mathrm{NaCl}$-soluble to -insoluble collagen in fibroblast cultures derived from patients with the Marfan syndrome (2). Increased amounts of salt-soluble collagen were observed in skin of patients with the Marfan syndrome (3). Metachromatic material thought to be chondroitin sulfate was found in the hearts and aortas of six patients (4), and a two- to fourfold increase of glycosaminoglycan $(G A G)^{1}$ excretion in Marfan patients has been reported (5).

The studies of Danes and Bearn (6) and of Matalon and Dorfman (7) have established that excessive amounts of GAGs accumulate in skin fibroblasts cultured from patients with mucopolysaccharidoses. The presence of degradative defects in mucopolysaccharidoses, originally suggested by Van Hoof and Hers (8), was confirmed by kinetic studies of Frantantoni, Hall, and Neufeld (9) and was more firmly established by the demonstration of the absence of $\alpha$-L-iduronidase activity in Hurler's and Scheie's diseases by Matalon and Dorfman (10) and Bach, Friedman, Weissman, and Neufeld (11), and of the absence of $N$-acetyl- $\alpha$-Dglucosaminidase in Sanfilippo B disease by O'Brien (12) and Von Figura and Kresse (13).

Matalon and Dorfman observed metachromasia in fibroblasts cultured from patients with Marfan's disease and found that the excess GAG was primarily hyaluronic acid (14). Skin fibroblasts cultured from normal individuals contain primarily hyaluronic acid in contrast to the excessive storage of dermatan sulfate in fibroblasts derived from Hurler's patients (7).

The purpose of this study was to examine the kinetics of GAG metabolism in fibroblasts cultured from patients with Marfan syndrome in order to determine

${ }^{1}$ Abbreviations used in this paper: CPC, cetylpyridinium chloride; GAG, glycosaminoglycan. 
whether the mechanism of GAG accumulation differs from that in Hurler's disease. The results confirm the presence of increased amounts of hyaluronic acid. Kinetic studies show no evidence of impaired degradation.

\section{METHODS}

Clinical summary. Skin explants were obtained from four patients with the Marfan syndrome. Three (F. G., G. G., and P. G.) were siblings while the fourth (Wa.) was unrelated. The father of the $G$. siblings was tall and thin and died at age 34 of a ruptured thoracic aneurysm. He was known to have had poor eyesight. The paternal uncle reportedly is similarly affected but is living in Italy and could not be contacted for this study.

F. G. is a 19-yr-old white man, $6 \mathrm{ft} 2$ inches tall with long hyperextensible fingers, a high arched palate, subluxed lens of the right eye, and an ejection murmur in the aortic area. The ascending aorta, aortic arch, and pulmonary artery are dilated as shown by angiography. No aortic insufficiency was detectable at the time of the study $4 \mathrm{yr}$ ago. Homocystine was not present in the urine.

P. G. is a 21-yr-old man with pectus carinatum, loosejointedness, superiorly subluxed right lens, widened ascending aorta, and left ventricular hypertrophy demonstrated by X-ray. An electrocardicgram showed mild left axis deviation, and cardiac catheterization studies did not show shunting. Chromatography of the urine did not show homocystine or hydroxyproline.

G. G. is a 23-yr-old woman. She is $5 \mathrm{ft} 7$ inches tall and has pectus carinatum, severe myopia in one eye, and a loud precordial late systolic murmur. Cardiac catheterization studies showed a large left atrium with mitral regurgitation. Homocystine was not present in the urine.

A second sister is $25 \mathrm{yr}$ old, is $4 \mathrm{ft} 11$ inches tall and has no signs of the Marfan syndrome. None of the G. family was mentally retarded or had the skin or osteoporotic changes of homocystinuria.

Wa. is a 39-yr-old white male salesman, $7 \mathrm{ft}$ tall with elongated fingers and toes, pectus excavatum, inguinal hernias, and ectopia lentis. He had severe aortic insufficiency and has undergone cardiac surgery and aortic valve replacement. Urine examination for homocystine was negative. Many others in his family were said to be tall with poor eyesight, but there was no recollection of heart disease.

Materials. Sodium $\left[1-{ }^{14} \mathrm{C}\right]$ acetate (sp. act $61 \mathrm{mCi} / \mathrm{mM}$ ) was obtained from New England Nuclear, Boston, Mass., and $\mathrm{D}-\left[\mathrm{U}-{ }^{14} \mathrm{C}\right]$ glucosamine (sp. act. $40 \mathrm{mCi} / \mathrm{mM}$ ) from Schwarz Bio Research, Inc., Orangeburg, N. Y. Cycloheximide was obtained from The Upjohn Co., Kalamazoo, Mich.

Media and trypsin solutions were obtained from Grand Island Biological Co., Grand Island, N. Y., crude papain was purchased from the Sigma Chemical Co., St. Louis, Mo. and twice crystallized by Dr. Lennart Rodén (15), testicular hyaluronidase (type VI, 3500 National Formulary U/mg) from Sigma Chemical Co., streptococcal hyaluronidase from Lederle Laboratories, Pearl River, N. Y., and chondroitinase ABC from Seikagaku Kogyo Co., Ltd., Tokyo, Japan. p-Nitrophenyl and 4-methylumbelliferone substrates were from Koch-Light Laboratories Ltd., Colnbrook, Bucks, England or Sigma Chemical Co. Carrier hyaluronic acid from human umbilical cord and chondroitin 4-sulfate prepared from bovine nasal septum were kindly supplied by Dr. A. J. Cifonelli.
Cell culture. The cells were grown in $100-\mathrm{mm}$ plastic tissue culture dishes (Falcon, Division of B-D Laboratories, Inc., Los Angeles, Calif.) using Dulbecco-Vogt-modified Eagle's medium containing $10 \%$ calf serum and $10 \%$ fetal calf serum $(7)$. Glutamine $(2 \mathrm{mM} / 100 \mathrm{ml})$, sodium bicarbonate $(5 \mathrm{ml}$ of an $8.4 \%$ solution per $100 \mathrm{ml})$, penicillin ( $50 \mathrm{U} / \mathrm{ml})$, and streptomycin $(50 \mu \mathrm{g} / \mathrm{ml})$ were added before use. The plates were maintained in $10 \% \mathrm{CO}_{2}, 90 \%$ air at $37^{\circ} \mathrm{C}$ and $100 \%$ humidity, and the medium was changed twice weekly. $\mathrm{pH}$ of the culture medium was monitored with a Coleman Model 39 meter (Coleman Instruments, Maywood, IIl.) or by comparing the color of culture fluids with buffered standards containing methyl red. The $\mathrm{pH}$ was 7.5 immediately after changing media and $\mathrm{CO}_{2}$ equilibration, but fell to 6.8 by the third day. In experiments comparing cells from Marfan and normal patients, cultures were used that had been through about the same number of transfers, usually three to six. The normal and Marfan cells, which showed a doubling time of $36 \mathrm{~h}$, were grown for $3 \mathrm{wk}$, by which time multiplication had ceased. The number of cells and amount of protein and DNA were approximately the same at the start of each experiment for the Marfan and the control plates.

The cells were fed the day before pulse labeling when sodium $\left[1-{ }^{14} \mathrm{C}\right]$ acetate $(2 \mu \mathrm{Ci} / \mathrm{ml})$ or $\left[\mathrm{U}^{14} \mathrm{C}\right]$ glucosamine $(0.5 \mu \mathrm{Ci} / \mathrm{ml})$ was added for varying periods of time. For studies involving analysis of extracellular GAG, the media was decanted and combined with two washes with cold Hanks' balanced salt solution. Cells were collected by scraping from the plate with a rubber policeman before sonication and protein determination (16) or were treated with trypsin $(0.25 \%)$-EDTA and were counted with a hemocytometer. Cells were monitored for mycoplasma weekly and with each transfer by aerobic and anaerobic incubation on solid agar freshly prepared according to the method of Hayflick (17).

Analytical methods. Isolation and characterization of GAGs were carried out by two methods. One involved digestion with crystalline papain, dialysis, concentration, addition of carrier hyaluronic acid and chondroitin 4-sulfate, followed by precipitation with cetylpyridinium chloride (CPC) as previously described (7). The other involved papain digestion followed by gel filtration on columns $(0.6 \times 100 \mathrm{~cm})$ of Sephadex G-75, G-100, or G-200 (Pharmacia Fine Chemicals Inc., Uppsala, Sweden). The eluant was $0.2 \mathrm{M} \mathrm{NaCl}$ with $0.2 \%$ sodium azide as a preservative The excluded material was dialyzed and concentrated, and aliquots were digested with testicular hyaluronidase or streptococcal hyaluronidase in $0.15 \mathrm{M}$ sodium acetate- $0.1 \mathrm{M}$ sodium chloride buffer, $\mathrm{pH} 4.5$ (18), or with chondoitinase $\mathrm{ABC}$ in $0.05 \mathrm{M}$ Tris acetate at $\mathrm{pH} 8.0$ for $3 \mathrm{~h}$ at $37^{\circ} \mathrm{C}$ (19). These digested samples, along with similarly incubated aliquots without enzymes, were rechromatographed on columns $(20 \times 0.9 \mathrm{~cm})$ of Sephadex G-50 (fine) with the same eluant. Digestion by any of the three enzymes led to retardation of more than $90 \%$ of the excluded counts from both Marfan and control preparations. Control experiments showed that the streptococcal hyaluronidase preparation did not digest chondroitin sulfate.

$\beta$-Galactosidase, $\alpha$-fucosidase and $\beta$-glucosidase activities were determined with the appropriate $p$-nitrophenyl derivatives as substrates. $\beta$-Glucosidase, $\beta$-glucuronidase, $\alpha$-galactosidase, $\beta$-xylosidase, and $\beta$ - $N$-acetyl hexosaminidase were assayed with the 4-methylumbelliferyl derivates as substrates (8). All were performed at $\mathrm{pH}$ 4.0-4.5. 
TABLE I

$\left[{ }^{14} \mathrm{C}\right]$ Acetate Incorporation into Hyaluronidase-Digestible and CPC-Precipitable Material

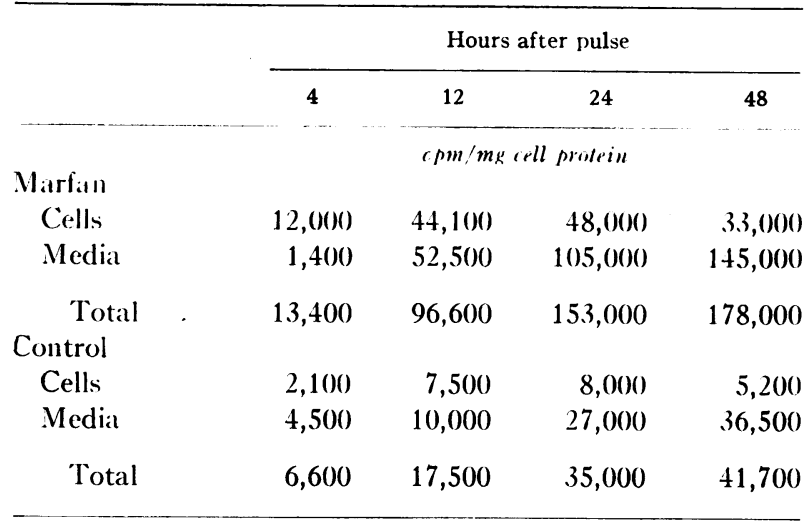

Uronic acid was determined by the carbazole method of Dische (20), and hexosamine was analyzed by the Boas modification of the Elson-Morgan method (21). DNA was assayed by the method of Burton (22).

Radioactivity was measured in a Packard Tri-Carb liquid scintillation spectrometer (Packard Instrument Co., Inc., Downers Grove, Ill.), with 2,5-diphenyloxazole-dimethyl 1,4-bis [2-(5-phenyloxazole)] benzene in toluene-ethanol (7).

\section{RESULTS}

Fibroblasts cultured from each of the patients with Marfan's disease accumulated abundant metachromatic material as shown by toluidine blue staining. Control

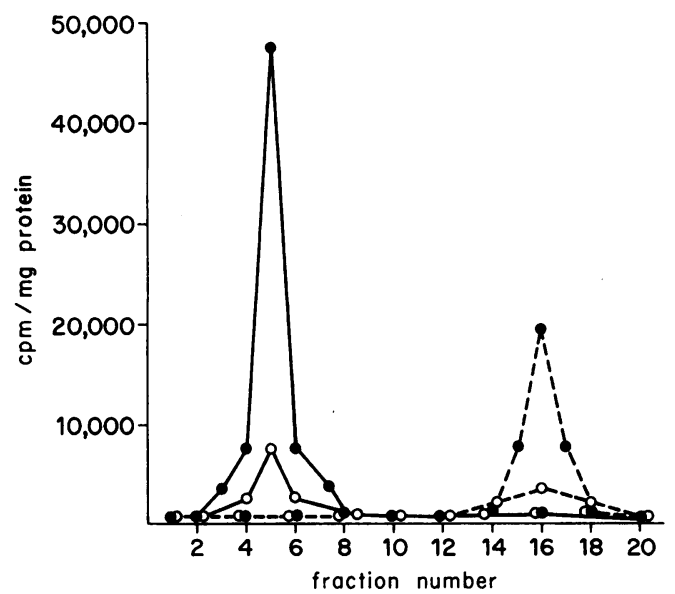

Figure 1 Effect of streptococcal hyaluronidase on Sephadex G-100-excluded material from Marfan fibroblasts labeled after a $\left[1-{ }^{14} \mathrm{C}\right]$ sodium acetate pulse for $24-48 \mathrm{~h}$. Aliquots of cells and media were digested with papain and that volume excluded from G-100 was incubated for $3 \mathrm{~h}$ with and without streptococcal hyaluronidase and rechromatographed on $\mathrm{G}-100$. $-\longrightarrow$, media and $\mathrm{O}-\mathrm{O}$, cells not incubated with hyaluronidase; and $\bullet-.-\bullet$, media and $\bigcirc--\bigcirc$, cells after incubation with hyaluronidase.
TABLE II

Accumulation of Glycosaminoglycan in the Media after a 24-h $\left[{ }^{14} \mathrm{C}\right]$ Glucosamine Pulse

\begin{tabular}{|c|c|c|}
\hline Subject & Condition & $\begin{array}{l}\mathrm{cpm} / \mathrm{mg} \\
\text { cell protein }\end{array}$ \\
\hline P. G. & Marfan & 36,000 \\
\hline Ii. & Marfan & 25,000 \\
\hline IIa. & Marfan & $28,00(0)$ \\
\hline H. & Control & 8,000 \\
\hline$M i$. & Control & 7,500 \\
\hline B. & Control & 7,000 \\
\hline Baby G. & $\begin{array}{l}\text { Clinically uninvolved } \\
\text { child of P. G. }\end{array}$ & 6,000 \\
\hline
\end{tabular}

fibroblasts showed no such staining. Metachromasia seemed to become more prominent as the cultures became more confluent but did not vary with number of transfers.

Marfan-derived fibroblasts incorporated an amount of $\left[{ }^{14} \mathrm{C}\right]$ acetate into $\mathrm{CPC}$-precipitable material several times greater than did control fibroblasts. Table I represents a typical experiment. With fibroblasts obtained from different Marfan and control patients, similar data were obtained in six separate experiments. Differences between the GAG content of Marfan and controls were greater in the media than in the cells. The radioactivity of the CPC-precipitable material in the media continued to increase while that in the cells began to fall after $24 \mathrm{~h}$, probably due to a decrease in specific activity of the intracellular precursor pool.

Electrophoresis on cellulose acetate strips of the isolated material in both media and cells showed that $90 \%$ of the radioactivity migrated as did authentic hyaluronic acid. Preincubation with streptococcal hyaluronidase resulted in complete disappearance of counts in the hyaluronate region. Treatment with testicular or streptococcal hyaluronidase also caused displacement of at least $90 \%$ of the counts from the G-100-excluded volume to the retarded volume of preparations from both Marfan cells and media (Fig. 1). When $\left[{ }^{14} \mathrm{C}\right]$ glucosamine was used as a precursor, identical results were obtained. These results indicate that the counts were primarily in hyaluronic acid.

Separate experiments were performed with a $\left[{ }^{14} \mathrm{C}\right]-$ glucosamine pulse using different patient and control fibroblasts. After papain digestion, the media was passed over Sephadex G-75. The radioactive material excluded from the column again showed a several-fold increase in samples from Marfan fibroblast cultures over that of controls when corrected to equivalent cell protein concentrations (Table II). 


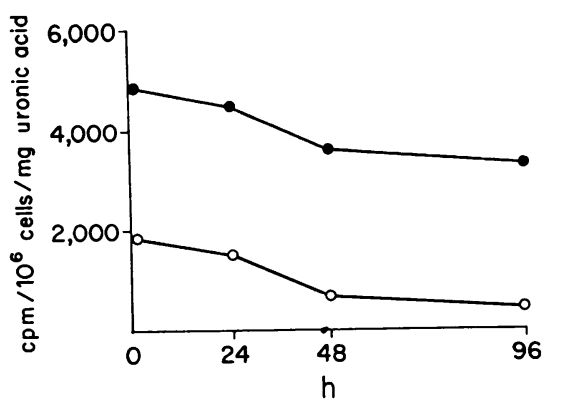

Figure 2 Comparison of the loss of ${ }^{14} \mathrm{C}$-labeled CPCprecipitable material from Marfan, —— and control, $\mathrm{O}-\mathrm{O}$ fibroblasts after a $\left[{ }^{14} \mathrm{C}\right]$ acetate pulse for $48 \mathrm{~h}$.

In the chase experiments, Marfan and control cultures were allowed to accumulate radioactivity by labeling for $48 \mathrm{~h}$ with $\left[{ }^{14} \mathrm{C}\right]$ acetate, after which time the labeled media were replaced with normal media. Cells were recovered from replicate plates after various periods of time and GAGs were isolated by the CPC method (Fig. 2). There appeared to be no significant differences between Marfan and control cells in the rate of removal of GAGs.

The experiment was repeated with $\left[{ }^{14} \mathrm{C}\right]$ glucosamine and a change of media every day for 6 days after an initial 24-h pulse. Figure 3 illustrates the rate of disappearance of radioactivity from streptococcal hyaluronidase-digestible GAGs isolated from the cells. Initial high rates of loss were observed, which were probably due to material adhering to the surface of the cells. If we exclude the first 20 -h period, there were parallel rates of loss of labeled GAGs from control fibroblasts and fibroblasts from Marfan patients. The first-order rate constant for the loss of glucosamine-labeled GAG was $\mathrm{k}=0.0104$, and the half-life of the GAG was 66 $\mathrm{h}$ with no statistical differences between control and Marfan fibroblasts.

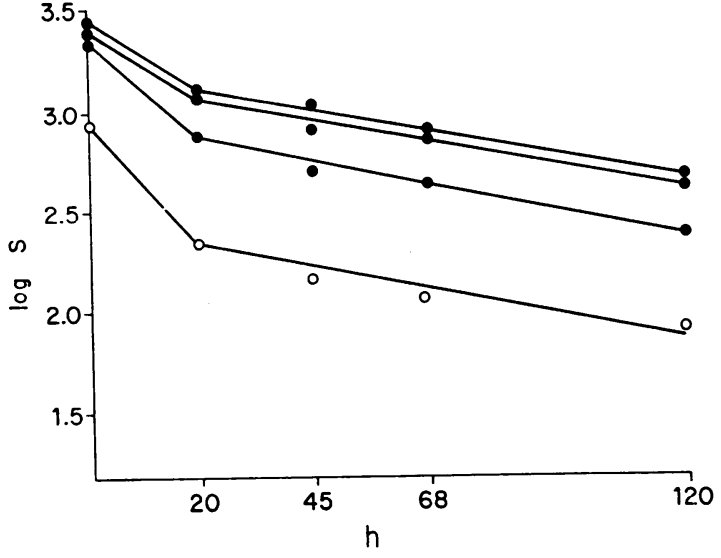

Figure 3 Rate of loss of high molecular weight hyaluronidase-digestible material from fibroblasts of Marfan, 0 , and control, $\bigcirc-O$. Log $S$ is the $\log _{10}$ of the counts per minute per milligram of cell protein at each designated time period.

Assays for $\beta$-glucuronidase, $\beta$ - $N$-acetyl hexosaminidase, $\beta$-galactosidase, $\beta$-xylosidase, $\beta$-glucosidase, and $\alpha$-L-fucosidase did not show striking decreases of activity in extracts of Marfan's fibroblasts as compared to controls (Table III).

Marfan fibroblasts and control fibroblasts were mixed in approximately equal numbers and grown to confluency (3 wk) along with each strain separately. The radioactivity incorporated into the $\mathrm{CPC}$-precipitable fraction after $\left[{ }^{14} \mathrm{C}\right]$ glucosamine pulsing was equal to the average of the Marfan and the control fibroblasts.

About $10^{7}$ Marfan fibroblasts were incubated with $100 \mu \mathrm{Ci}\left[{ }^{14} \mathrm{C}\right]$ acetate for $48 \mathrm{~h}$ to prepare hyaluronate of high specific activity. The hyaluronate was isolated with the CPC method and shown to be susceptible to hyaluronidase digestion. Cell-free extracts of Marfan and control fibroblasts prepared by sonication and multiple freeze-thawings were incubated at $37^{\circ} \mathrm{C}$ for up to

TABLE III

Glycosidase Actizities

\begin{tabular}{llcc}
\hline \multicolumn{1}{c}{ Enzyme } & \multicolumn{1}{c}{ Substrate } & Marfan & Control \\
\hline & & pmol released $/ \mathrm{mg}$ cell protein \\
$\beta$-Glucosidase & $p$-Nitrophenyl- $\beta$-D-glucopyranoside & $430-470$ & $168-190$ \\
$\beta$-Glucosidase & 4-Methylumbelliferyl- $\beta$-D-glucopyranoside & 250 & $115-130$ \\
$\beta$-Galactosidase & $p$-Nitrophenyl- $\beta$-D-galactopyranoside & $865-955$ & $774-860$ \\
$\alpha$-Fucosidase & $p$-Nitrophenyl- $\alpha$-D-fucopyranoside & $364-455$ & $189-214$ \\
$\beta$-Glucuronidase & 4-Methylumbelliferyl- $\beta$-D-glucopyranoside & 2,650 & $3,300-3,90()$ \\
$\beta$ - $N$-acetyl- & 4-Methylumbelliferyl- $N$-acetyl- & 5,600 & $4,850-4,900)$ \\
hexosaminidase & $\beta$-D-galactosaminide & & \\
$\beta$-Galactosidase & 4-Methylumbelliferyl- $\beta$-D-galactopyranuside & 10,750 & $8,8509,700$ \\
$\beta$-Xylosidase & 4-Methylumbelliferyl- $\beta$-D-xylopyranoside & 0.35 & 0.15 \\
\hline
\end{tabular}


TABLE IV

$\left[{ }^{14} \mathrm{C}\right]$ Glucosamine Incorporation into High Molecular Weight Hyaluronidase-Digestible Material after Incubation with or without Cycloheximide $(10 \mu \mathrm{g} / \mathrm{ml})$. Cells and Media were Combined

\begin{tabular}{rccr} 
& $\begin{array}{c}\text { Without } \\
\text { cycloheximide }\end{array}$ & Cycloheximide & Fall of GAG \\
\hline & total cpm/mg protein $($ media + cells $)$ & $\%$ \\
Marfan F. G. & 76,600 & 62,400 & $18 \%$ \\
G. G. & 57,300 & 54,700 & $5 \%$ \\
Control K. & 22,900 & 19,500 & $15 \%$ \\
\hline
\end{tabular}

$24 \mathrm{~h}$ in acetate/chloride $\mathrm{pH} 4.5$ buffer with the labeled substrate (see Methods). Filtration of samples removed at 0,3 , and $24 \mathrm{~h}$ on $\mathrm{G}-100$ showed that the hyaluronate had not been degraded in either preparation. This is consistent with other studies from this laboratory, in which hyaluronidase activity had not been observed in cultured fibroblasts. ${ }^{2}$

Cycloheximide $(10 \mu \mathrm{g} / \mathrm{ml})$ was then incubated with cultures of Marfan and control fibroblasts for $14 \mathrm{~h}$ in $100-\mathrm{mm}$ Falcon dishes containing $10 \mathrm{ml}$ media. After the first $2 \mathrm{~h}$ of this incubation, $\left[{ }^{14} \mathrm{C}\right]$ glucosamine $(0.5$ $\mu \mathrm{Ci} / \mathrm{ml})$ was added. The experiment was terminated $12 \mathrm{~h}$ later. Separate experiments had shown that the amount of cycloheximide used caused a $95 \%$ inhibition of $\left[\mathrm{U}-{ }^{14} \mathrm{C}\right]$ leucine incorporation into total protein. Some of the plates of Marfan and control cells were additionally incubated with $\left[\right.$ methyl $\left.-{ }^{3} \mathrm{H}\right]$ thymidine $(0.1 \mu \mathrm{Ci} / \mathrm{ml})$ for $4 \mathrm{~h}$ before termination of the experiment, that is, after $10 \mathrm{~h}$ of cycloheximide incubation. The counts incorporated into DNA in the cycloheximide-treated cultures had fallen to $3-8 \%$ of the counts incorporated into DNA in the control plates (23).

Assay of $\left[{ }^{14} \mathrm{C}\right]$ glucosamine incorporated into high molecular weight material (excluded on G-100) digested with streptococcal hyaluronidase showed a decrease in total (media plus cells) GAG of $5-18 \%$ in both Marfan and normal fibroblasts treated with cycloheximide (Table IV). This difference was mainly due to a lesser amount of labeled high molecular weight material in the media, which represented $90 \%$ of the total counts. The counts isolated from the washed fibroblasts themselves actually rose two- to fourfold when incubated with cyclohexinide compared to controls. This fibroblast-associated high molecular weight material was also digested with both testicular and streptococcal hyaluronidase.

In these experiments, the cycloheximide incubation was longer than that generally used $(7,24)$ to maximize the effect of GAG degradation. An additional result of the long incubation was a drastic fall of DNA

\footnotetext{
'Unpublished observation of the authors.
}

synthesis, and therefore the data remain difficult to interpret.

\section{DISCUSSION}

The enzymic basis has now been established for a large number of ganglioside, glycosphingolipid, and mucopolysaccharide storage diseases (25). Accumulation in lysosomes of partially degraded materials occurs as a result of deficient enzymic activity of specific lysosomal hydrolases (8). These diseases are recessive. In contrast, little is known of the biochemical mechanisms of dominant diseases. McKusick has suggested that dominant diseases may be characterized by a defect in structural proteins, because half-replacement of a structural protein might be expected to result in an abnormal phenotype, but half-replacement of an enzyme may not affect the phenotype (26).

GAGs isolated from Marfan and control cultured fibroblasts after $\left[{ }^{14} \mathrm{C}\right]$ acetate or $\left[{ }^{14} \mathrm{C}\right]$ glucosamine pulses confirmed the increased accumulation in Marfan's fibroblasts noted earlier. Electrophoretic and enzyme susceptibility studies indicated that this GAG was predominately hyaluronic acid. Isolation and further characterization of the material had been done earlier in this laboratory and was not repeated (14). When GAG was quantitated, it was found that it was being amassed in the media in far greater amounts than in the cells.

Since the increase in the amount of labeled GAG in Marfan fibroblasts could result from either an increase in the rate of synthesis or a decrease in the rate of degradation, the kinetics of loss from the cells of previously labeled material were studied. It was shown that the polysaccharide disappeared from the Marfan cells at the same rate as from the control fibroblasts.

The activity of lysosomal degradative enzymes toward a number of synthetic sugar glycosides was not decreased in Marfan's compared to control fibroblast extracts. Cell-free extracts of Marfan's fibroblasts did not differ from control extracts in capacity to degrade isotopically prelabeled high molecular weight GAG. It thus appears that the hyaluronic acid accumulates in greater amounts in the fibroblasts from patients with Marfan's disease because of a greater rate of synthesis rather than a decreased rate of degradation.

It has not been possible to study the mechanism of the increased rate of hyaluronic acid synthesis, since little is known of the factors that control the rate of biosynthesis of this compound. Whether hyaluronic acid exists in mammalian tissues as a protein complex is not yet conclusively established. Whereas biosynthetic studies have established that inhibitors of protein synthesis (cycloheximide and puromycin) inhibits synthesis of sulfated GAGs, studies on hyaluronic acid synthesis have heen equivocal (24). The data presented 
here show that cycloheximide causes a minimal inhibition of hyaluronic acid synthesis in fibroblasts derived from both normal individuals and patients with the Marfan syndrome.

It is difficult to determine at this time whether increased hyaluronic acid synthesis represents the primary defect in Marfan's syndrome and accounts for the characteristic pathology of the disease. In previous studies it had been demonstrated that some increase in hyaluronic acid content occurs in Hurler fibroblasts (7). Germinario, Kahlenberg, and Pinsky (27) have recently claimed this represents an increase in synthesis. There is considerable evidence that sulfated GAGs interact with collagen (28). It is possible that the presence of excessive amounts of hyaluronic acid in the ground substance might interfere with the appropriate formation of collagen (or elastic fibers) and result in a change in the mechanical properties of tissues.

\section{ACKNOWLEDGMENTS}

We are grateful for helpful discussions with Drs. J. A. Cifonelli and A. C. Stoolmiller.

This investigation was supported by the National Institutes of Health Research Grant no. AM 05996, HD 04583, General Research Grant 5-SO1 RR-05367-11, and Medical Training Grant RO1 AM 05263-13 and a grant from the Chicago and Illinois Heart Association.

\section{REFERENCES}

1. McKusick, V. A. 1966. Heritable Disorders of Connective Tissue. The C. C. Mosby Company, St. Louis, Mo. 3rd edition. 41-109.

2. Macek, M., J. Hurych, M. Chvapil, and V. Kadlecová. 1966. Study on fibroblasts in Marfan's syndrome. Humangenetik. 3: 87.

3. Laitinen, O., J. Uitto, M. Iivanainen, M. Hannuksela, and K. I. Kivirikko. 1968. Collagen metabolism of the skin in Marfan's syndrome. Clin. Chim. Acta. 21: 321.

4. Bolande, R. P. 1963. The nature of the connective tissue abiotrophy in the Marfan syndrome. Lab. Invest. 12: 1087.

5. Berenson, G. S., and E. R. Dalferes. 1965. Urinary excretion of mucopolysaccharides in normal individuals and in the Marfan syndrome. Biochim. Biophys. Acta. $101: 183$

6. Danes, B. S., and A. G. Bearn. 1966. Hurler's syndrome: a genetic study in cell culture. J. Exp. Med. $123: 1$.

7. Matalon, R., and A. Dorfman. 1966. Hurler's syndrome : biosynthesis of acid mucopolysaccharides in tissue culture. Proc. Natl. Acad. Sci. U. S. A. 56: 1310.

8. Van Hoof, F., and H. G. Hers. 1968. The abnormalities of lysosomal enzymes in mucopolysaccharidoses. Eur. $J$. Biochem. 7: 34 .

9. Frantantoni, J. C., C. W. Hall, and E. F. Neufeld. 1968. Defect in Hurler's and Hunter's syndromes- faulty degradation of mucopolysaccharide. Proc. Natl. Acad. Sci. U. S. A. $60: 699$.

10. Matalon, R., and A. Dorfman. 1972. Hurler's syndrome, an $\alpha$-L-iduronidase deficiency. Biochem. Biophys. Res. Commun. 47: 959.

11. Bach, G., R. Friedman, P. Weissman, and E. F. Neufeld. 1972. The defect in the Hurler and Scheie syndromes: deficiency of $\alpha$-L-iduronidase. Proc. Natl. Acad. Sci. U. S. A. $69: 2048$.

12. O'Brien, J. S. 1972. Sanfilippo syndrome: profound deficiency of alpha-acetylglucosaminidase activity in organs and skin fibroblasts from type B patients. Proc. Natl. Acad. Sci. U.S. A. $69: 1720$.

13. Von Figura, K., and H. Kresse. 1972. The Sanfilippo B corrective factor: a $N$-acetyl- $\alpha$-D-glucosaminidase. Biochem. Biophys. Res. Commun. 48: 262.

14. Matalon, R.. and A. Dorfman. 1968. The accumulation of hyaluronic acid in cultured fibroblasts of the Marfan syndrome. Biochem. Biophys. Res. Commun. 32: 150 .

15. Kimmell, J. R., and E. L. Smith. 1954. Crystalline papain: preparation, specificity, and activation. J. Biol. Chem. 207: 515.

16. Lowry, O. H., N. J. Rosebrough, A. L. Farr, and R. J. Randall. 1951. Protein measurement with the folin phenol reagent. J. Biol. Chem. 193: 265.

17. Hayflick, L. 1965. Tissue culture and mycoplasmas. Tex. Rep. Biol. Med. 23 (Suppl. 1) : 285.

18. Mathews, M. B., S. Roseman, and A. Dorfman. 1951. Determination of the chondroitinase activity of bovine testicular preparations. J. Biol. Chem. 188: 327 .

19. Yamagata, T., H. Saito, O. Habuchi, and S. Suzuki. 1968. Purification and properties of bacterial chondroitinases and chondrosulfatases. J. Biol. Chem. 243: 1523.

20. Dische, Z. 1947. A new specific color reaction of hexuronic acids. J. Biol. Chem. $167: 189$.

21. Boas, N. F. 1953. Method for the determination of hexosamines in tissues. J. Biol. Chem. 204: 553.

22. Burton, K. 1956. A study of the conditions and mechanism of the diphenylamine reaction for the colorimetric estimation of DNA. Biochemistry. 62: 315.

23. Conrad, A. H., and F. H. Ruddle. 1972. Regulation of thymidylate synthetase activity in cultured mammalian cells. J. Cell Sci. 10: 471.

24. Smith, C., and D. Hamerman. 1968. Partial inhibition by cycloheximide of hyaluronate synthesis in cell culture. Proc. Soc. Exp. Biol. Med. 127: 988.

25. Stanbury, J. B., J. B. Wyngaarden, and D. S. Fredrickson. 1972. $\mathrm{G}_{\mathbf{M} 2}$ gangliodoses: Tay-Sachs disease. In The Metabolic Basis of Inherited Disease. McGraw-Hill Book Co., New York. 3rd edition. 615-807, 1218-1272.

26. McKusick, V. A. 1971. Mendelian Inheritance in Man. Johns Hopkins Press, Baltimore, Md., 3rd edition xi.

27. Germinario, R. J., A. Kahlenberg, and L. Pinsky. 1973. The disorder of hyaluronic acid metabolism in cultured skin fibroblasts derived from a patient with the Hurler Syndrome. Biochem. J. 132: 403 .

28. Öbrink, B., and A. Wasteson. 1971. Nature of the interaction on chondroitin 4-sulfate and chrondroitin sulfate-proteoglycan with collagen. Biochem. J. 121: 227. 